\title{
Regional $\left[{ }^{18} \mathrm{~F}\right]$ flortaucipir PET is more closely associated with disease severity than CSF p-tau in Alzheimer's disease
}

\author{
Emma E. Wolters ${ }^{1,2}$ (D) $\cdot$ Rik Ossenkoppele ${ }^{2,3} \cdot$ Sander C. J. Verfaillie $^{1} \cdot$ Emma M. Coomans $^{1} \cdot$ Tessa Timmers $^{1,2} \cdot$ \\ Denise Visser ${ }^{1,2}$ • Hayel Tuncel ${ }^{1}$ - Sandeep S. V. Golla ${ }^{1}$ - Albert D. Windhorst ${ }^{1} \cdot$ Ronald Boellaard $^{1}$ • Wiesje M. van \\ der Flier ${ }^{2,4} \cdot$ Charlotte E. Teunissen $^{5} \cdot$ Philip Scheltens $^{2} \cdot$ Bart N. M. van Berckel $^{1}$
}

Received: 11 December 2019 / Accepted: 4 March 2020 / Published online: 14 April 2020

(C) The Author(s) 2020

\begin{abstract}
Purpose In vivo Alzheimer's disease (AD) biomarkers for tau pathology are cerebrospinal fluid (CSF) phosphorylated tau (p-tau) and $\left[{ }^{18} \mathrm{~F}\right]$ flortaucipir positron emission tomography (PET). Our aim was to assess associations between CSF p-tau with $\left[{ }^{18} \mathrm{~F}\right]$ flortaucipir PET and the associations of both tau biomarkers with cognition and atrophy.

Methods We included 78 amyloid positive cognitively impaired patients (clinical diagnoses mild cognitive impairment (MCI, $n=8$ ) and $\mathrm{AD}$ dementia $(n=45)$ and 25 cognitively normal subjects with subjective cognitive decline (SCD) (40\% amyloid-positive)). Dynamic $130 \mathrm{~min}\left[{ }^{18} \mathrm{~F}\right]$ flortaucipir PET scans were acquired to generate binding potential $\left(\mathrm{BP}_{\mathrm{ND}}\right)$ images using receptor parametric mapping and standardized uptake values ratios of 80-100 $\min \left(\mathrm{SUVr}_{80-100 \mathrm{~min}}\right)$ post injection. We obtained regional $\mathrm{BP}_{\mathrm{ND}}$ and $\mathrm{SUVr}$ from entorhinal, limbic, and neocortical regions-of-interest (ROIs), closely aligning to the neuropathological tau staging schemes. Cognition was assessed using MMSE and composite scores of four cognitive domains, and atrophy was measured using gray matter volume covering the major brain lobes. First, we used linear regressions to investigate associations between CSF p-tau (independent variable) and tau PET (dependent variable). Second, we used linear regressions to investigate associations between CSF p-tau, tau PET (separate independent variables, model 1), and cognition (dependent variable). We then assessed the independent effects of CSF p-tau and tau PET on cognition by simultaneously adding the other tau biomarker as a predictor (model 2). Finally, we performed the same procedure for model 1 and 2, but replaced cognition with atrophy. Models were adjusted for age, sex, time lag between assessments, education (cognition only), and total intracranial volume (atrophy only).

Results Higher $\left[{ }^{18} \mathrm{~F}\right]$ flortaucipir $\mathrm{BP}_{\mathrm{ND}}$ was associated with higher CSF p-tau (range of standardized betas ( $\mathrm{s} \beta$ ) across ROIs, $0.43-0.46$; all $p<0.01)$. $\left[{ }^{18} \mathrm{~F}\right]$ flortaucipir $\mathrm{BP}_{\mathrm{ND}}$ was more strongly associated with cognition and atrophy than CSF $\mathrm{p}$-tau. When $\left[{ }^{18} \mathrm{~F}\right]$ flortaucipir $\mathrm{BP}_{\mathrm{ND}}$ and CSF $\mathrm{p}$-tau were entered simultaneously, $\left[{ }^{18} \mathrm{~F}\right]$ flortaucipir $\mathrm{BP}_{\mathrm{ND}}$ (range $\mathrm{s} \beta=-0.20$ to -0.57 , all $p<0.05$ ) was strongly associated with multiple cognitive domains and atrophy regions. SUVr showed comparable results to $\mathrm{BP}_{\mathrm{ND}}$.

Conclusion Regional $\left[{ }^{18} \mathrm{~F}\right]$ flortaucipir $\mathrm{BP}_{\mathrm{ND}}$ correlated stronger with cognition and neurodegeneration than CSF p-tau, suggesting that tau PET more accurately reflects disease severity in AD.
\end{abstract}

This article is part of the Topical Collection on Neurology

Electronic supplementary material The online version of this article (https://doi.org/10.1007/s00259-020-04758-2) contains supplementary material, which is available to authorized users.

Emma E. Wolters

ee.wolters@amsterdamumc.nl

1 Department of Radiology and Nuclear Medicine, Amsterdam Neuroscience, Vrije Universiteit Amsterdam, Amsterdam UMC, Amsterdam, The Netherlands

2 Alzheimer Center Amsterdam, Department of Neurology, Amsterdam Neuroscience, Vrije Universiteit Amsterdam, Amsterdam UMC, Amsterdam, The Netherlands
3 Clinical Memory Research Unit, Lund University, Lund, Sweden

4 Department of Epidemiology and Biostatistics, Vrije Universiteit Amsterdam, Amsterdam UMC, Amsterdam, The Netherlands

5 Neurochemistry Laboratory, Department of Clinical Chemistry, Vrije Universiteit Amsterdam, Amsterdam UMC, Amsterdam, The Netherlands 
Keywords $\left[{ }^{18} \mathrm{~F}\right]$ flortaucipir $\cdot \mathrm{PET} \cdot \mathrm{CSF} \cdot \mathrm{Tau} \cdot$ Cognition $\cdot$ Atrophy

\section{Introduction}

Alzheimer's disease (AD) is characterized neuropathologically by depositions of amyloid plaques and hyperphosphorylated tau. Postmortem studies have revealed that tau pathology is highly associated with the degree of cognitive impairment [1-3] and thus may serve as a biomarker of disease severity. In vivo tau can be captured in cerebrospinal fluid (CSF) and by positron emission tomography (PET). CSF phosphorylated tau (p-tau) is thought to reflect an $\mathrm{AD}$-specific hyperphosphorylated state of tau [4]. $\left[{ }^{18} \mathrm{~F}\right]$ flortaucipir is currently the most widely used PET tau tracer, which binds with high affinity to the paired helical filaments (PHFs) of tau in $\mathrm{AD}$ [5-7].

Although both are in vivo biomarkers for tau pathology, it remains unclear whether CSF p-tau and $\left[{ }^{18} \mathrm{~F}\right]$ flortaucipir PET provide interchangeable or complementary information. So far, a number of studies have investigated associations between $\left[{ }^{18} \mathrm{~F}\right]$ flortaucipir PET and CSF p-tau. Some studies found moderate to strong correlations across groups which consisted mainly of cognitively normal individuals $[8,9]$, while others could not replicate these findings [10]. Across the AD continuum, strongest associations between tau PET and CSF p-tau were mostly observed in later, dementia stages [11]. In addition, similar high levels were observed in CSF ptau in prodromal $\mathrm{AD}$ and $\mathrm{AD}$ dementia, while $\left[{ }^{18} \mathrm{~F}\right]$ flortaucipir uptake values continued to increase with progression of $\mathrm{AD}$ [12]. Taken together these results indicate that the relationship between CSF p-tau biomarkers and $\left[{ }^{18} \mathrm{~F}\right]$ flortaucipir may depend on disease severity.

Both CSF p-tau $[13,14]$ and $\left[{ }^{18} \mathrm{~F}\right]$ flortaucipir $[15-21]$ have been related separately to proxies of disease severity, for example, to worse cognitive performance [13, 15-19] and a greater degree of atrophy [14, 18-21]. Despite these similarities, they may still differ on various aspects. $\left[{ }^{18} \mathrm{~F}\right]$ flortaucipir PET is able to capture regional uptake patterns and mirrors established neuropathological staging schemes of tau $[15,22]$, while correlations of CSF p-tau with neuropathological tau burden have been modest [23, 24]. However, CSF p-tau may be more sensitive in detecting early changes in AD (tau) pathology $[11,25,26]$. Few studies have described the relationship between both CSF p-tau and $\left[{ }^{18} \mathrm{~F}\right]$ flortaucipir binding with proxies of disease severity, and it remains to be established whether $\left[{ }^{18} \mathrm{~F}\right]$ flortaucipir PET and $\mathrm{p}$-tau can be viewed as equivalent markers for $\mathrm{AD}$ staging.

Therefore, we aimed to compare CSF and PET markers of tau pathology and to assess their relationship with cognitive impairment and atrophy as proxies of disease severity. We first examined regional associations between CSF p-tau and quantitative $\left[{ }^{18} \mathrm{~F}\right]$ flortaucipir binding in cognitively normal and impaired subjects on the AD pathophysiological continuum $[27,28]$. Second, to investigate whether CSF p-tau biomarkers and $\left[{ }^{18} \mathrm{~F}\right]$ flortaucipir PET provide complementary information regarding disease severity, we investigated associations of both CSF p-tau and $\left[{ }^{18} \mathrm{~F}\right]$ flortaucipir PET with multiple cognitive domains and regional atrophy.

\section{Methods}

\section{Participants}

We included 78 subjects from the Amsterdam Dementia Cohort $[29,30]$, of whom 25 were cognitively normal with subjective cognitive decline (SCD), and 53 were cognitively impaired (mild cognitive impairment (MCI) due to AD [31] $(n=8)$ or probable AD dementia [32] $(n=45))$.

We grouped the MCI-AD and probable AD dementia subjects into one MCI/AD group.

All subjects underwent a standardized dementia screening, including medical history, extensive neuropsychological assessment, physical and neurological examination, lumbar puncture, blood tests, electroencephalography, and brain magnetic resonance imaging (MRI) [30]. Diagnosis was established by consensus in a multidisciplinary meeting [29, 30].

The label of SCD [33], which were used as controls, was provided based on self-reported cognitive complaints but without any objective impairment in performance on cognitive or neurological tasks or brain damage as evidenced by MRI. SCD subjects with evidence of substantial $A \beta$ pathology after visual reading of $S_{U V R} R_{50-70}$ of $\left[{ }^{18} \mathrm{~F}\right]$ florbetapir Aß-PET scans [34] were classified as amyloid positive subjects.

The diagnosis of MCI/AD met core clinical criteria [31,32] according to the National Institute on Aging and Alzheimer's Association (NIA-AA) and were biomarker supported, an AD like CSF (i.e., tau/A $\beta 42$ fraction $>0.52$ [35]) and/or a positive $\mathrm{A}$ B-PET $\left(\left[{ }^{11} \mathrm{C}\right] \mathrm{PiB}\right.$ or $\left[{ }^{18} \mathrm{~F}\right]$ florbetaben $)$ scan by visual assessment $[36,37]$.

Exclusion criteria for all participants were (1) diagnosis of dementia not due to $\mathrm{AD}$, (2) significant cerebrovascular disease on MRI (e.g., major CVA), (3) major traumatic brain injury, (4) major psychiatric or neurological disorders other than $\mathrm{AD}$, (5) recent substance abuse, and (6) a time lag between LP and tau-PET imaging $>2$ years. The study protocol was approved by the Medical Ethics Review Committee of the Amsterdam UMC, location VU Medical center. All patients provided written informed consent. 


\section{CSF biomarkers}

CSF samples were obtained from LP between the L3/L4, L4/ L5, or L5/S1 intervertebral space and collected in polypropylene tubes using a 25-gauge needle and syringe [29]. To assess CSF biomarker levels, analyses were performed at the Neurochemistry Laboratory of the Department of Clinical Chemistry of the Amsterdam UMC according to international guidelines [38]. Levels of $A \beta_{1-42}$, t-tau, and p-tau (phosphorylated at threonine 181) in CSF were determined using sandwich ELISAs (Innotest $\beta$-AMYLOID (1-42), Innotest hTAU$\mathrm{Ag}$, and Innotest PhosphoTAU-181p, Fujirebio (formerly Innogenetics), Belgium), and $A \beta 1-42$ levels were corrected for drift in kit performance over time [39]. Cutoff values for abnormal CSF (A $\beta 1-42<813 \mathrm{pg} / \mathrm{mL}$ [39]), t-tau ( $>375 \mathrm{pg} /$ $\mathrm{mL})$, and $\mathrm{p}$-tau ( $>52 \mathrm{pg} / \mathrm{mL}$ ) [40] were used to define an AD like positive CSF profile (i.e., tau/A $\beta 42$ fraction $>0.52$ [35]) supportive of the diagnosis of MCI/AD. In this sample, $\mathrm{p}$-tau and t-tau were highly correlated $(r=0.98, p<0.01)$; therefore, all main analyses were performed with $\mathrm{p}$-tau, and results for $\mathrm{t}-$ tau are provided in the Supplementary Material.

\section{Neuropsychological examination}

The Mini-Mental State Examination (MMSE) was used as a measure of global cognitive status [41]. In addition, we assessed four cognitive domains [42] including memory (Dutch version of the Rey Auditory Verbal Learning Test immediate recall and delayed recall, Visual Association Test (VAT) version A), attention (Digit span Forward, Trial Making Test [TMT] version A), Stroop word and color naming), executive functioning (Digit span Backward, TMT version B, letter fluency test (D-A-T) and Stroop color-word interference test), and language (VAT-A naming and category fluency version animals). Trail Making Tests and Stroop tests were inverted so that lower scores indicated worse performance. For cognitive domain scores, we created composite scores by averaging Z-scores for each individual test within a domain (with a minimum of two tests per domain). The percentages of missing data for the cognitive domains were $10.3 \%$ (attention), $11.5 \%$ (memory), $12.8 \%$ (language), and $19.2 \%$ (executive functioning). As a sensitivity analysis we repeated our analyses including subjects without missing data $(n=59$, see Supplementary Table 1$)$.

\section{MRI imaging and processing}

All subjects underwent a 3D-T1 weighted sequence on a 3.0 Tesla MRI scanner (Ingenuity TF PET/MR, Philips Medical Systems, Best, The Netherlands, $n=75$ ), Vantage Titan (Toshiba Medical Systems, Otawara, Japan, $n=2$ ), and a Signa HDxT (GE Healthcare, Milwaukee, WI, $n=1$ ). All MR images were performed within a maximum of 12 months from the $\left[{ }^{18} \mathrm{~F}\right]$ flortaucipir PET scan for SCD subjects (medi$\mathrm{an}=0.2, \mathrm{IQR}=1.3$ ) and a maximum of 6 months from the $\left[{ }^{18} \mathrm{~F}\right]$ flortaucipir PET scan for subjects with MCI/AD (median $=0.1$, IQR $=0.2$ ).

We calculated gray matter (GM) volumes using voxelbased morphometry (VBM) implemented in Statistical Parametric Mapping (SPM) version 12 software (Wellcome Trust Center for Neuroimaging, University College London, UK) as described previously [43]. Structural T1-weighted MR images were segmented into gray matter, white matter, and cerebrospinal fluid. Quality control was performed on all gray matter native space images. Next, images were normalized to Montreal Neurological Institute (MNI) 152 space, using a study specific template created with the DARTEL toolbox. Whole brain gray matter maps were smoothed with an $8 \mathrm{~mm}$ full-width at half-maximum Gaussian kernel. We extracted regional gray matter volumes from the automatic anatomic labeling (AAL) using a priori defined cortical ROIs covering all the major brain lobes [43]: medial/lateral temporal, medial/ lateral parietal, and occipital and frontal lobes (see Supplementary Table 2) based on the AAL atlas.

Total intracranial volume (TIV) was calculated by combining the native space segmentations (gray matter, white matter, and CSF) for each subject. We used gray matter density (i.e., gray matter volume corrected for TIV) as a proxy of atrophy in the analyses.

\section{$\left[{ }^{18} \mathrm{~F}\right]$ flortaucipir imaging and processing}

Dynamic $130 \mathrm{~min}\left[{ }^{18} \mathrm{~F}\right]$ flortaucipir PET scans were acquired on a Philips Ingenuity TF-64 PET/CT scanner. The scanning protocol consisted of two dynamic PET scans of 60 and $50 \mathrm{~min}$, respectively, with a 20 -min break in between [44, 45]. The first 60 min dynamic scan started simultaneously with a bolus injection $234 \pm 16 \mathrm{MBq}\left[{ }^{18} \mathrm{~F}\right]$ flortaucipir (injected mass $1.17 \pm 0.78 \mu \mathrm{g}$ ). The second PET scan was co-registered to the first dynamic PET scan using Vinci software [46]. PET list mode data were rebinned into a total of 29 frames $(1 \times 15,3 \times 5,3 \times 10,4 \times 60,2 \times 150,2 \times 300,4 \times$ 600 , and $10 \times 300$ seconds) and reconstructed using $3 \mathrm{D}$ RAMLA with a matrix size of $128 \times 128 \times 90$ and a final voxel size of $2 \times 2 \times 2 \mathrm{~mm}^{3}$, including standard corrections for dead time, decay, attenuation, random, and scatter. The 3D-T1 MR images were co-registered to the averaged images (frame 8-29) of the PET scan.

The T1-weighted images were co-registered to their corresponding PET images using Vinci (volume imaging in neurological imaging) software [46]. Volumes of interest (VOI, Hammers template [47]) were subsequently delineated on the MR images and superimposed on the PET scan using PVElab [48]. Binding potential $\left(\mathrm{BP}_{\mathrm{ND}}\right)$ was generated using receptor parametric mapping (RPM) with whole cerebellar gray matter as a reference region (extracted from the 
Hammers template [47]). SUVr images were generated for the time interval $80-100$ min post injection. $\mathrm{BP}_{\mathrm{ND}}$ (or SUVr) images were resliced to FreeSurfer coordinates and using a MarsBar package in SPM12, $\mathrm{BP}_{\mathrm{ND}}$ (or SUVr) was extracted in the following a priori defined FreeSurfer regions-of-interest (ROIs) on spatially normalized MR images: entorhinal, limbic, and neocortical regions. These ROIs closely aligning the neuropathological tau staging schemes, adjusted from Scholl et al. [15] (see Supplementary Table 3).

\section{Statistical analysis}

Statistical analyses were performed using Statistical Package for the Social Sciences (SPSS, IBM version 22) and R (v. 3.2.3, The $\mathrm{R}$ foundation for Statistical computing).

Differences in demographic, clinical, and AD biomarker characteristics between disease groups were assessed using analyses of variance for continuous variables and $\chi^{2}$ for dichotomous data.

Linear regression models were performed to assess the relationship between entorhinal, limbic, and neocortical $\left[{ }^{18} \mathrm{~F}\right]$ flortaucipir $\mathrm{BP}_{\mathrm{ND}}$ (as dependent variable) and CSF ptau (as independent variable), adjusted for age, sex, and time lag between LP and tau PET. We performed the analyses across all subjects and additionally stratified for diagnosis (i.e., SCD subjects and MCI/AD) and amyloid status for SCD subjects only. We did not stratify for amyloid status for the rest of the analyses because of the limited amount of amyloid positive SCD subjects $(n=10)$.

In order to investigate spatial associations between CSF ptau (independent variable) and $\left[{ }^{18} \mathrm{~F}\right]$ flortaucipir $\mathrm{BP}_{\mathrm{ND}}$ (or SUVr) (dependent variable), we performed a voxel-wise multiple regression analysis for CSF $\mathrm{p}$-tau and $\left[{ }^{18} \mathrm{~F}\right]$ flortaucipir PET, adjusted for age, sex, and time lag between LP and $\left[{ }^{18} \mathrm{~F}\right]$ flortaucipir PET scan. All resulting t-maps were thresholded with $p<0.001$ at the voxel-level. Data are shown with and without correction for family-wise error $p<0.05$.

Linear regression models were performed to assess the relationships between CSF p-tau and 3 a priori defined $\left[{ }^{18} \mathrm{~F}\right]$ flortaucipir ROIs on PET with cognition. First, we assessed the predictive effects of CSF p-tau and entorhinal, limbic, and neocortical $\left[{ }^{18} \mathrm{~F}\right]$ flortaucipir separately (model 1), followed by a model including both predictors (model 2: CSF p-tau + neocortical $\left[{ }^{18} \mathrm{~F}\right]$ flortaucipir or entorhinal/limbic/neocortical $\left[{ }^{18} \mathrm{~F}\right]$ flortaucipir + CSF p-tau as predictors). Additionally, both models were adjusted for age, sex, education, and time lag between PET/CSF assessments. Finally, we repeated the aforementioned procedure, but replaced cognition with gray matter atrophy (dependent variable) additionally adjusted for TIV.

In addition, all regressions were repeated by replacing $\mathrm{BP}_{\mathrm{ND}}$ with $\mathrm{SUVr}_{80-100 \mathrm{~min}}$ and were repeated by replacing CSF p-tau by t-tau. The results for t-tau are presented in the
Supplementary Material. Results were comparable for CSF ptau and t-tau for all analysis.

For all linear regressions, standardized beta's $(\mathrm{s} \beta)$ were used as an outcome variable. By standardizing all variables in the equation, we obtain an easy interpretable outcome measure, which is comparable across regressions. The $s \beta$ is the change in the outcome variable for 1 standard deviation in change of the predictor. All s $\beta$ 's are tested against the null hypothesis that an $s \beta$ of 0 yields no effect [49].

\section{Results}

\section{Demographics}

Subject characteristics are presented in Table 1. Subjects were $64.8 \pm 6.5$ years old and as expected MCI/AD participant had a lower MMSE score of $23 \pm 4(p<0.01)$. In addition, CSF ptau and $\left[{ }^{18} \mathrm{~F}\right]$ flortaucipir $\mathrm{BP}_{\mathrm{ND}}$ within all brain regions were higher in $\mathrm{MCI} / \mathrm{AD}$ patients compared to SCD subjects (all $p<0.01)$.

\section{The relationship between CSF $p$-tau and $\left[{ }^{18} \mathrm{~F}\right]$ flortaucipir $\mathrm{BP}_{\mathrm{ND}}$}

Associations between CSF p-tau and tau PET are presented in Table 2. Using all subjects CSF p-tau was associated with higher $\left[{ }^{18} \mathrm{~F}\right]$ flortaucipir $\mathrm{BP}_{\mathrm{ND}}$ in the entorhinal cortex $(\mathrm{s} \beta=$ $0.46)$, limbic $(s \beta=0.45)$, and neocortical region $(s \beta=0.43$ ), all $p<0.01$. Within-group correlations were stronger for SCD subjects than for $\mathrm{MCI} / \mathrm{AD}$ patients, with strongest correlations seen in the limbic region ( $\mathrm{s} \beta=0.59, \mathrm{p}<0.01$, Table 2, Fig. 1). Within the SCD subjects, the relationship between CSF p-tau and $\left[{ }^{18} \mathrm{~F}\right]$ flortaucipir $\mathrm{BP}_{\mathrm{ND}}$ was driven by the amyloid positive individuals (Fig. 1). Note that the variance of the SCD subjects patients is smaller than for $\mathrm{MCI} / \mathrm{AD}$ patients, therefore a more gradual slope is observed for association between CSF p-tau and limbic, neocortical tau, although $s \beta s$ are stronger for SCD. Comparable results were seen for CSF t-tau (Supplementary Table 4, Supplementary Fig. 1).

Voxel-wise analyses across all subjects showed significant associations between widespread cortical $\left[{ }^{18} \mathrm{~F}\right]$ flortaucipir binding (right $>$ left binding) and CSF p-tau. In SCD subjects, associations between tau PET and CSF p-tau were mainly observed in temporoparietal regions, whereas in MCI/AD this association was observed in the fronto-temporo-parietal areas (Fig. 2). All results survived family-wise error corrections, except for the results in the MCI/AD group. CSF t-tau showed a comparable, although marginally more widespread pattern than p-tau (Supplementary Fig. 2). 
Table 1 Demographic, clinical, and AD biomarker characteristics over the total sample and per disease group

\begin{tabular}{|c|c|c|c|c|c|}
\hline & $\operatorname{SCD} \mathrm{A} \beta+(n=10)$ & $\operatorname{SCD} \mathrm{A} \beta-(n=15)$ & $\mathrm{MCI} / \mathrm{AD}(n=53)$ & Total Sample $(n=78)$ & Total SCD $(n=25)$ \\
\hline Age, years & $67 \pm 6$ & $64 \pm 6$ & $65 \pm 7$ & $65 \pm 7$ & $65 \pm 6$ \\
\hline Female, $\%$ & $60 \%$ & $60 \%$ & $53 \%$ & $43 \%$ & $60 \%$ \\
\hline No. $A ß$ positive subjects & $10(100 \%)$ & $0(0 \%)$ & $53(100 \%)$ & $63(81 \%)$ & $10(40 \%)$ \\
\hline Education, Verhage scale, median(range) & $6(4-7)$ & $6(2-7)$ & $6(3-7)$ & $6(2-7)$ & $6(2-7)$ \\
\hline Time lag LP/PET, years & $0.7 \pm 0.6$ & $0.9 \pm 0.5$ & $0.6 \pm 0.5$ & $0.7 \pm 0.5$ & $0.8 \pm 0.7$ \\
\hline \multicolumn{6}{|l|}{ Neuropsychological measures } \\
\hline $\operatorname{MMSE}(n=78)$ & $28 \pm 1$ & $28 \pm 1$ & $23 \pm 4^{b}$ & $25 \pm 4$ & $28 \pm 1$ \\
\hline $\operatorname{Memory}^{c}(n=78)$ & $-0.5 \pm 0.8$ & $0.3 \pm 0.6$ & $-3.1 \pm 2.1^{\mathrm{b}}$ & $-2.1 \pm 2.3$ & $-0.0 \pm 0.8$ \\
\hline Attention $^{d}(n=73)$ & $-0.2 \pm 0.6$ & $0.1 \pm 0.6$ & $-1.3 \pm 1.2^{\mathrm{b}}$ & $-0.9 \pm 1.2$ & $-0.0 \pm 0.6$ \\
\hline Language $^{e} \quad(n=68)$ & $-0.0 \pm 0.4$ & $0.0 \pm 0.8$ & $-1.0 \pm 1.0^{\mathrm{b}}$ & $-0.6 \pm 1.0$ & $-0.0 \pm 0.7$ \\
\hline Executive functioning ${ }^{f}(n=73)$ & $-0.1 \pm 0.9$ & $-0.1 \pm 0.7$ & $-2.4 \pm 1.0^{\mathrm{b}}$ & $-0.9 \pm 1.1$ & $0.0 \pm 0.8$ \\
\hline \multicolumn{6}{|l|}{ Tau biomarkers } \\
\hline \multicolumn{6}{|l|}{ CSF } \\
\hline $\mathrm{CSF} A \beta_{1-42}$ & $779 \pm 197$ & $1067 \pm 217$ & $541 \pm 113^{\mathrm{b}}$ & $677 \pm 260$ & $966 \pm 247$ \\
\hline CSF t-tau & $615 \pm 383$ & $257 \pm 201$ & $760 \pm 412^{\mathrm{bd}}$ & $645 \pm 422$ & $401 \pm 333$ \\
\hline CSF p-tau & $83 \pm 36$ & $43 \pm 23$ & $90 \pm 35^{\mathrm{b}}$ & $80 \pm 38$ & $59 \pm 38$ \\
\hline \multicolumn{6}{|l|}{$\left[{ }^{18} \mathrm{~F}\right]$ flortaucipir PET } \\
\hline Entorhinal cortex $\mathrm{BP}_{\mathrm{ND}}$ & $0.2 \pm 0.2$ & $-0.1 \pm 0.1$ & $0.3 \pm 0.2^{\mathrm{b}}$ & $0.2 \pm 0.2$ & $-0.0 \pm 0.2$ \\
\hline Limbic region $\mathrm{BP}_{\mathrm{ND}}$ & $0.2 \pm 0.1$ & $0.0 \pm 0.0$ & $0.4 \pm 0.2^{\mathrm{b}}$ & $0.3 \pm 0.2$ & $0.1 \pm 0.1$ \\
\hline Neocortex $\mathrm{BP}_{\mathrm{ND}}$ & $0.1 \pm 0.1$ & $-0.0 \pm 0.0$ & $0.3 \pm 0.3^{\mathrm{b}}$ & $0.2 \pm 0.3$ & $0.0 \pm 0.1$ \\
\hline Entorhinal cortex SUVr & $1.0 \pm 0.1$ & $1.3 \pm 0.2$ & $1.5 \pm 0.2^{\mathrm{b}}$ & $1.4 \pm 0.3$ & $1.1 \pm 0.2$ \\
\hline Limbic region SUVr & $1.1 \pm 0.1$ & $1.3 \pm 0.2$ & $1.5 \pm 0.2^{\mathrm{b}}$ & $0.4 \pm 0.3$ & $1.2 \pm 0.1$ \\
\hline Neocortex SUVr & $1.1 \pm 0.1$ & $1.2 \pm 0.2$ & $1.4 \pm 0.3^{\mathrm{b}}$ & $1.3 \pm 0.3$ & 1. \pm 0.1 \\
\hline
\end{tabular}

Continuous data shown as mean \pm standard deviation, unless specified otherwise. Differences in demographic, clinical, and AD biomarker characteristics between disease groups were assessed using ANOVA for continuous variables and $\chi^{2}$ for dichotomous data

${ }^{\mathrm{a}}$ Significantly different from SCD subjects at $p<0.05 .{ }^{\mathrm{b}}$ Significantly different from SCD subjects at $p<0.01$

${ }^{\mathrm{c}} \mathrm{Z}$-score memory domain, ${ }^{\mathrm{d}} \mathrm{Z}$-score attention domain, ${ }^{\mathrm{e}} \mathrm{Z}$-score language domain, ${ }^{\mathrm{f}} \mathrm{Z}$-score executive functioning domain

\section{Associations between CSF p-tau and $\left[{ }^{18} \mathrm{~F}\right]$ flortaucipir $\mathrm{BP}_{\mathrm{ND}}$ and cognition}

Associations between CSF p-tau and tau PET and cognition are presented in Table 3 and Supplementary Table 1. Across the total group, all tau PET ROIs correlated to all cognitive scores: MMSE and the memory, attention and executive functioning, and language (model 1 with tau PET as a predictor; range $\mathrm{s} \beta=-0.23$ to -0.64 , all $p<0.05)$. Contrary, CSF $\mathrm{p}$-tau showed only associations with MMSE and memory (model 1 ; range $s \beta$ 's $=-0.26$ to -0.44 , all $p<0.01$, Table 3).
Table 2 Standardized $\beta$ coefficients for the relationship between CSF p-tau and entorhinal, limbic, and neocortical $\left[{ }^{18} \mathrm{~F}\right]$ flortaucipir $\mathrm{BP}_{\mathrm{ND}}$ or $\mathrm{SUVr}$ over the total sample and stratified per disease group

\begin{tabular}{llll}
\hline & $\begin{array}{l}\text { Total sample } \\
(n=78)\end{array}$ & $\begin{array}{l}\mathrm{SCD} \\
(n=25)\end{array}$ & $\begin{array}{l}\text { MCI/AD } \\
(n=53)\end{array}$ \\
CSF p-tau & CSF p-tau & 0. -tau \\
\hline Entorhinal $\left[{ }^{18} \mathrm{~F}\right]$ flortaucipir BP & $\mathbf{0 . 4 6}(p<0.01)$ & $0.43(p=0.07)$ & $0.17(p=0.17)$ \\
Limbic $\left[{ }^{18} \mathrm{~F}\right]$ flortaucipir $\mathrm{BP}_{\mathrm{ND}}$ & $\mathbf{0 . 4 5}(p=<0.01)$ & $\mathbf{0 . 5 9}^{\mathbf{a}}(p=0.01)$ & $0.22(p=0.08)$ \\
Neocortical $\left[{ }^{18} \mathrm{~F}\right]$ flortaucipir $\mathrm{BP}$ & $\mathbf{0 . 4 3}(p=<0.01)$ & $\mathbf{0 . 5 4}(p=0.02)$ & $\mathbf{0 . 2 7}(p=0.03)$ \\
Entorhinal $\left[{ }^{18} \mathrm{~F}\right]$ flortaucipir SUVr & $\mathbf{0 . 5 0}(p=<0.01)$ & $\mathbf{0 . 5 9}(p<0.01)$ & $0.16(p=0.21)$ \\
Limbic $\left[{ }^{18} \mathrm{~F}\right]$ flortaucipir SUVr & $\mathbf{0 . 4 7}(p=<0.01)$ & $\mathbf{0 . 6 7}(p=0.00)$ & $0.21(p=0.09)$ \\
Neocortical $\left[{ }^{18} \mathrm{~F}\right]$ flortaucipir SUVr & $\mathbf{0 . 4 3}(p=<0.01)$ & $0.41(p=0.08)$ & $\mathbf{0 . 2 6}(p=0.03)$ \\
\hline
\end{tabular}

Standardized $\beta$ coefficients (significant in bold) from regression analysis with $\left[{ }^{18} \mathrm{~F}\right]$ flortaucipir $\mathrm{BP}_{\mathrm{ND}}$ or $\mathrm{SUVr}$ as the dependent variables and CSF $\mathrm{p}$-tau as predictor.

Effects adjusted for age, sex, and time lag between LP and $\left[{ }^{18} \mathrm{~F}\right]$ flortaucipir PET 

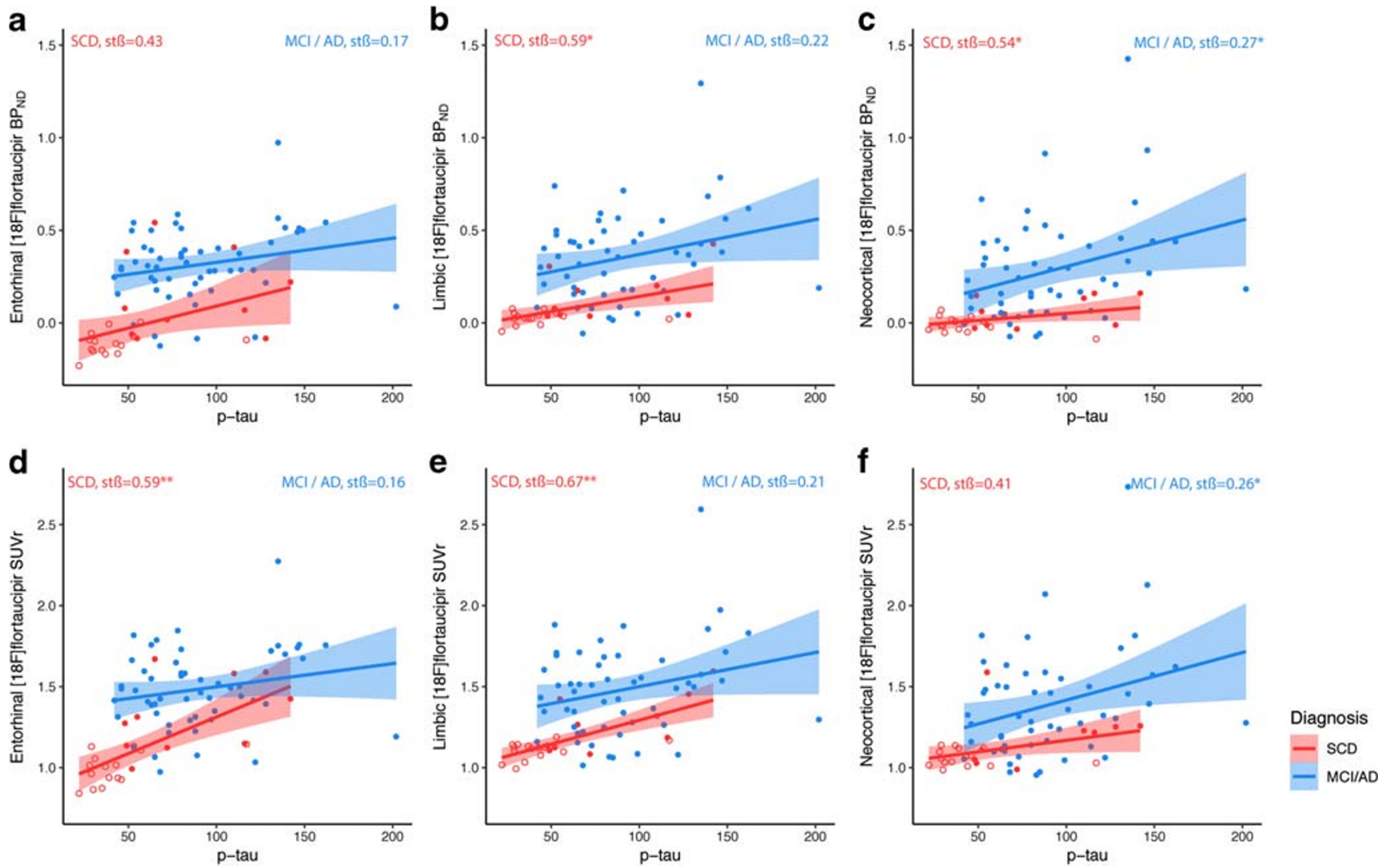

Fig. 1 Scatterplots of the observed relationship between CSF p-tau with entorhinal, limbic, and neocortical $\left[{ }^{18} \mathrm{~F}\right]$ flortaucipir $\mathrm{BP}_{\mathrm{ND}}$ (top row, $\mathbf{a}-\mathbf{c}$ ) and SUVr (bottom row, d-f). Each symbol represents one subject. The fitted lines

are stratified over $\mathrm{AD}$ (blue) and SCD subjects (red); closed circles are $\mathrm{A} \beta$ positive, open circles are $A \beta$ negative. Correlations were adjusted for age, sex, and time lag between LP and $\left[{ }^{18} \mathrm{~F}\right]$ flortaucipir PET scan

When entered simultaneously (model 2), associations between $\left[{ }^{18} \mathrm{~F}\right]$ flortaucipir $\mathrm{BP}_{\mathrm{ND}}$ and cognition (model 2, MMSE, memory, attention, executive functioning, and language; range $\mathrm{s} \beta$ 's $=-0.25$ to -0.57 , all $p<0.05$, Table 3) remained essentially comparable, but appeared strongly attenuated for CSF p-tau (model 2, MMSE; $\mathrm{s} \beta=-0.21, p<0.05$, Table 3).

After stratification, stronger associations were seen in MCI/ AD patients compared to SCD subjects. After correcting for the other biomarker (model 2), regional tau PET, but not CSF $\mathrm{p}$-tau, was related to MMSE (range $\mathrm{s} \beta$ 's $=-0.43$ to -0.45 , all $p<0.01$ ), attention (range $\mathrm{s} \beta$ 's $=-0.39$ to -0.45 , all $p<0.05$ ), and executive functioning (range $\mathrm{s} \beta$ 's $\mathrm{s}=-0.34$ to -0.41 , all $p<0.05$ ) within the MCI/AD patients. Comparable results for model 1 and model 2 were seen when replacing p-tau with t-tau (Supplementary Table 5).

\section{Associations between CSF p-tau and $\left[{ }^{18} \mathrm{~F}\right]$ flortaucipir $\mathrm{BP}_{\mathrm{ND}}$ and atrophy}

Associations between CSF p-tau and tau PET and atrophy are presented in Table 4. Across all subjects, associations were seen between high CSF p-tau with temporal, parietal, and occipital atrophy (model 1; range s $\beta$ 's =
-0.20 to -0.22 , all $p<0.05)$, but disappeared when adjusting for neocortical tau PET. All $\left[{ }^{18} \mathrm{~F}\right]$ flortaucipir ROIs were related to the different atrophy ROIs (model 1 ; range $\mathrm{s} \beta$ 's $=-0.27$ to -0.49 , all $p<0.05$ ), even after adjusting for CSF p-tau (model 2; range $s \beta$ 's $=-0.20$ to -0.51 , all $p<0.05$ ). After stratification, these results appeared largely attributable to MCI/AD participants, no significant associations were seen for the SCD subjects. Comparable results for t-tau are presented in Supplementary Table 6.

\section{SUVr vs $\mathrm{BP}_{\mathrm{ND}}$}

Although SUVr overestimated $\mathrm{BP}_{\mathrm{ND}}$ values (Table 1), comparable results were obtained for $\mathrm{SUVr}$ and $\mathrm{BP}_{\mathrm{ND}}$. Overall, higher $\mathrm{p}$-tau was related to higher entorhinal $(\mathrm{s} \beta=0.50)$, limbic $(\mathrm{s} \beta=0.47)$, and neocortical ( $\mathrm{s} \beta=0.43)\left[{ }^{18} \mathrm{~F}\right]$ flortaucipir $\mathrm{SUVr}$, all $p<0.01$ (Table 2). In line with $\mathrm{BP}_{\mathrm{ND}}$, within groups, correlations were stronger for SCD subjects, and strongest correlations were seen in the limbic region $(\mathrm{s} \beta=0.67$ $p<0.01$, Table 2, Fig. 1). Voxel-wise analysis confirmed comparable associations between $\left[{ }^{18} \mathrm{~F}\right]$ flortaucipir $\mathrm{BP}_{\mathrm{ND}}$ or $\mathrm{SUVr}$ and CSF p-tau (Fig. 2), and the associations with cognition 


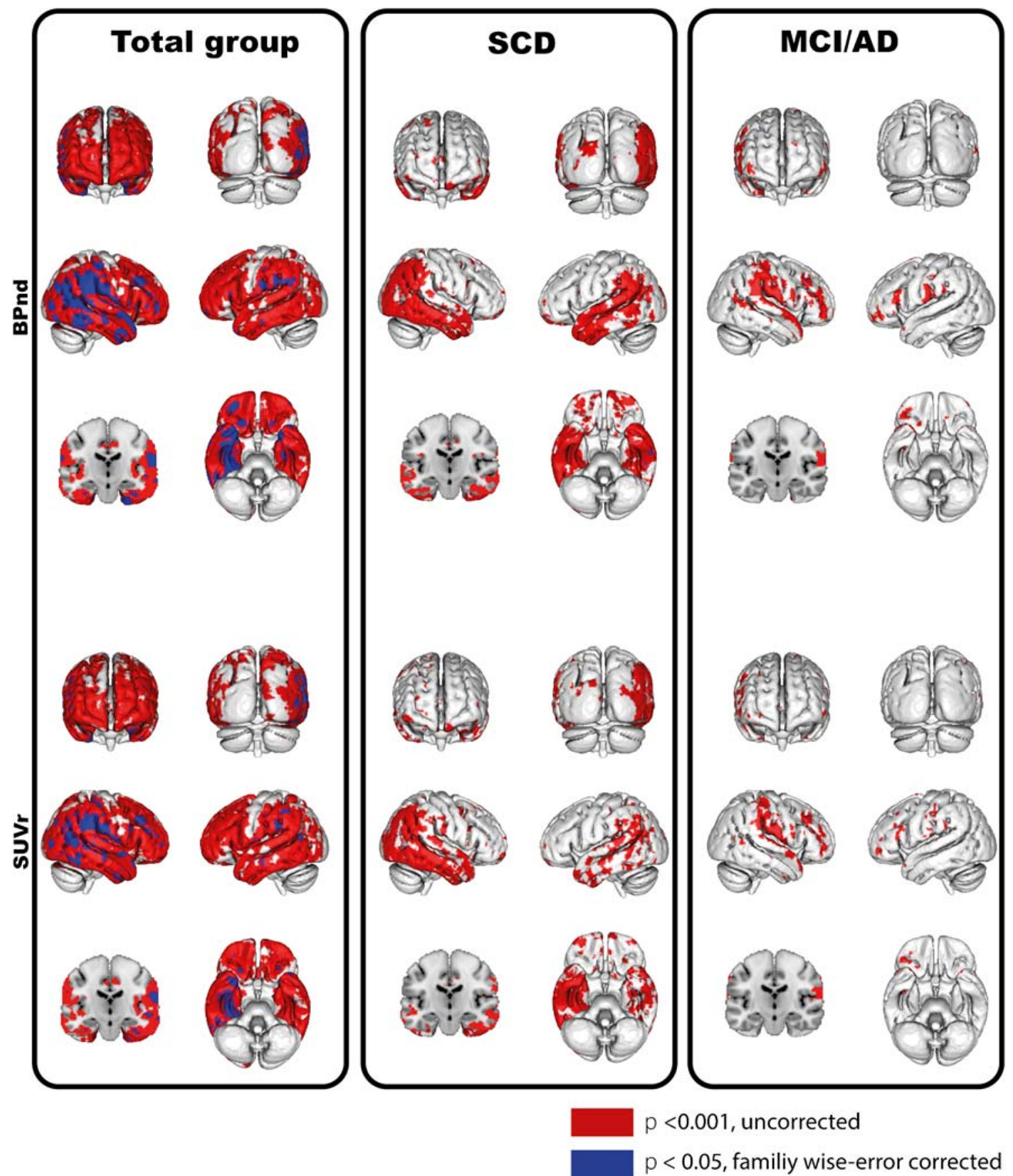

Fig. 2 Voxel-wise associations between CSF p-tau and $\left[{ }^{18} \mathrm{~F}\right]$ flortaucipir $\mathrm{BP}_{\mathrm{ND}}$ (top row) and SUvr (bottom row). Voxel-wise associations are shown using a threshold $p_{\text {uncorrected }}<0.001$ (red) and $p_{\text {FWEcorrected }}<0.05$ (blue) at the voxel

and atrophy were essentially the same for SUVr (Supplementary Tables 7, 8) and $\mathrm{BP}_{\mathrm{ND}}$ (Tables 3 and 4).

\section{Discussion}

In this study, we examined cross-sectional associations between CSF p-tau and quantitative $\left[{ }^{18} \mathrm{~F}\right]$ flortaucipir PET and their associations with cognition and atrophy. First, we found that higher CSF level. Contrasts were adjusted for age, sex, and time lag between LP and $\left[{ }^{18} \mathrm{~F}\right]$ flortaucipir PET scan. The associations were assessed in the total sample, within SCD subjects only and within MCI/AD subjects only

p-tau was only moderately correlated to higher $\left[{ }^{18} \mathrm{~F}\right]$ flortaucipir binding across the total group. Both tau markers were associated with disease severity, but we found stronger associations for $\left[{ }^{18} \mathrm{~F}\right]$ flortaucipir compared to CSF $\mathrm{p}$-tau in relation to cognition and atrophy, particularly for the MCI/AD group. Taken together, our findings suggest that tau PET may be a better biomarker for tracking Alzheimer's disease severity.

Our main finding was that tau PET, independently of CSF p-tau, was related to proxies of disease severity in AD. We 
Table 3 Standardized $\beta$ coefficients for the relationship between cognitive outcome and CSF p-tau or entorhinal, limbic, and neocortical $\left[{ }^{18} \mathrm{~F}\right]$ flortaucipir $\mathrm{BP}_{\mathrm{ND}}$ over the total sample and stratified per disease group

\begin{tabular}{|c|c|c|c|c|c|c|}
\hline & \multicolumn{2}{|c|}{$\begin{array}{l}\text { Total sample } \\
(n=78)\end{array}$} & \multicolumn{2}{|l|}{$\begin{array}{l}\text { SCD } \\
(n=25)\end{array}$} & \multicolumn{2}{|l|}{$\begin{array}{l}\mathrm{MCI} / \mathrm{AD} \\
(n=53)\end{array}$} \\
\hline & Model 1 & Model 2 & Model 1 & Model 2 & Model 1 & Model 2 \\
\hline \multicolumn{7}{|l|}{ CSF p-tau } \\
\hline MMSE & $-0.44^{\mathrm{b}}$ & $-0.21^{\mathrm{a}}$ & 0.07 & 0.20 & $-0.29^{\mathrm{a}}$ & -0.17 \\
\hline Memory & $-0.26^{\mathrm{a}}$ & -0.12 & -0.10 & 0.10 & -0.05 & -0.04 \\
\hline Attention & -0.18 & -0.01 & -0.16 & 0.08 & -0.05 & 0.03 \\
\hline Executive functioning & -0.14 & 0.06 & 0.28 & $0.48^{\mathrm{a}}$ & -0.03 & 0.07 \\
\hline Language & -0.10 & -0.00 & 0.11 & 0.32 & -0.00 & 0.01 \\
\hline \multicolumn{7}{|l|}{$\left[{ }^{18} \mathrm{~F}\right]$ flortaucipir $\mathrm{BP}_{\mathrm{ND}}$} \\
\hline \multicolumn{7}{|l|}{ Entorhinal region } \\
\hline MMSE & $-0.41^{b}$ & $-0.25^{\mathrm{a}}$ & -0.23 & -0.21 & -0.01 & -0.04 \\
\hline Memory & $-0.54^{b}$ & $-0.52^{b}$ & $-0.50^{b}$ & $-0.50^{\mathrm{a}}$ & -0.27 & -0.27 \\
\hline Attention & -0.14 & -0.35 & -0.17 & -0.14 & $0.43^{b}$ & $0.45^{\mathrm{b}}$ \\
\hline Executive functioning & $-0.29^{b}$ & $0.25^{\mathrm{a}}$ & 0.07 & -0.01 & 0.13 & 0.14 \\
\hline Language & $-0.23^{\mathrm{a}}$ & -0.22 & -0.18 & -0.41 & 0.20 & 0.21 \\
\hline \multicolumn{7}{|l|}{ Limbic region } \\
\hline MMSE & $-0.64^{b}$ & $-0.54^{b}$ & -0.22 & -0.20 & $-0.50^{b}$ & $-0.45^{b}$ \\
\hline Memory & $-0.46^{b}$ & $-0.41^{b}$ & -0.24 & -0.22 & -0.10 & -0.09 \\
\hline Attention & $-0.45^{b}$ & $-0.41^{b}$ & -0.29 & -0.32 & -0.22 & -0.21 \\
\hline Executive functioning & $-0.52^{b}$ & $-0.52^{b}$ & -0.06 & -0.23 & $-0.34^{\mathrm{a}}$ & $-0.34^{\mathrm{a}}$ \\
\hline Language & $-0.33^{b}$ & $-0.33^{\mathrm{a}}$ & -0.10 & -0.24 & -0.11 & -0.11 \\
\hline \multicolumn{7}{|l|}{ Neocortical region } \\
\hline MMSE & $-0.64^{b}$ & $-0.53^{b}$ & -0.17 & -0.13 & $-0.50^{b}$ & $-0.43^{b}$ \\
\hline Memory & $-0.38^{b}$ & $-0.29^{a}$ & -0.32 & -0.29 & 0.04 & 0.07 \\
\hline Attention & $-0.55^{b}$ & $-0.52^{b}$ & $-0.40^{\mathrm{a}}$ & -0.42 & $-0.38^{a}$ & $-0.39^{\mathrm{a}}$ \\
\hline Executive functioning & $-0.56^{b}$ & $-0.57^{b}$ & -0.16 & -0.31 & $-0.39^{\mathrm{a}}$ & $-0.41^{\mathrm{a}}$ \\
\hline Language & $-0.27^{\mathrm{a}}$ & -0.25 & -0.25 & -0.39 & 0.00 & 0.02 \\
\hline
\end{tabular}

Standardized $\beta$ coefficients (significant in bold) from multiple regression analysis with cognitive measures as the dependent variables and either CSF p-tau and/or $\left[{ }^{18} \mathrm{~F}\right]$ flortaucipir $\mathrm{BP}_{\mathrm{ND}}$ as predictors using separate analyses

Model $1=$ Either CSF p-tau or entorhinal/limbic/neocortical $\left[{ }^{18} \mathrm{~F}\right]$ flortaucipir $\mathrm{BP}_{\mathrm{ND}}$ was used as a predictor. Effects adjusted for age, sex, education, and time lag between cognitive testing and LP or $\left[{ }^{18} \mathrm{~F}\right]$ flortaucipir PET Model $2=\mathrm{CSF}$ p-tau + neocortical $\left[{ }^{18} \mathrm{~F}\right]$ flortaucipir $\mathrm{BP}_{\mathrm{ND}}$ or entorhinal/limbic/neocortical $\left[{ }^{18} \mathrm{~F}\right]$ flortaucipir $\mathrm{BP}_{\mathrm{ND}}+\mathrm{CSF}$ p-tau were used as predictors. Effects adjusted as model 1

${ }^{\text {a }}$ Significant standardized $\beta$ coefficient at $p<0.05$

${ }^{\mathrm{b}}$ Significant standardized $\beta$ coefficient at $p<0.01$ found associations between various $\left[{ }^{18} \mathrm{~F}\right]$ flortaucipir ROIs, recapitulating the neuropathological tau stages, and attention, memory, language, and executive functioning as well as with brain atrophy. Associations were most pronounced for MCI/ $\mathrm{AD}$ dementia patients, especially with regard to limbic and neocortical tau deposition and widespread latrophy, which suggest that later neuropathological tau stages measured by $\left[{ }^{18} \mathrm{~F}\right]$ flortaucipir $\mathrm{BP}_{\mathrm{ND}}$ are tightly related to neurodegeneration in clinical AD. In line with the previous studies [15, 22], we showed that tau PET aligns with the neuropathological tau stages by showing a temporoparietal pattern in the SCD subjects and greater involvement of frontal areas in AD subjects. Previous studies also showed stronger associations for frontal, temporal, and parietal tau PET with cognition $[11,50]$ and temporoparietal $\left[{ }^{18} \mathrm{~F}\right]$ flortaucipir with atrophy [11] compared to CSF p-tau in $\mathrm{AD}$, further supporting the use of especially tau PET to track disease severity. A possible explanation for these differences in associations could be that each tau biomarker reflects different aspects of tau pathology. CSF p-tau rises early in the disease course, possibly even before $A \beta$ PET positivity [51]. Additionally, extracellular soluble forms of pathological tau (as can be measured using CSF) may precede the intracellular aggregated hyperphosphorylated form of tau (as measured by $\left[{ }^{18} \mathrm{~F}\right]$ flortaucipir PET). Therefore, CSF may show greater disparity than tau 
Table 4 Standardized $\beta$ coefficients for the relationship between regional gray matter atrophy and CSF p-tau or $\left[{ }^{18} \mathrm{~F}\right]$ flortaucipir $\mathrm{BP}_{\mathrm{ND}}$ over the total sample and stratified per disease group

\begin{tabular}{|c|c|c|c|c|c|c|}
\hline & \multicolumn{2}{|c|}{$\begin{array}{l}\text { Total sample } \\
(n=78)\end{array}$} & \multicolumn{2}{|l|}{$\begin{array}{l}\text { SCD } \\
(n=25)\end{array}$} & \multicolumn{2}{|l|}{$\begin{array}{l}\mathrm{MCI} / \mathrm{AD} \\
(n=53)\end{array}$} \\
\hline & Model 1 & Model 2 & Model 1 & Model 2 & Model 1 & Model 2 \\
\hline \multicolumn{7}{|l|}{ CSF p-tau } \\
\hline Medial temporal & -0.15 & -0.01 & 0.18 & 0.25 & 0.03 & 0.08 \\
\hline Lateral temporal & $-0.21^{\mathrm{a}}$ & -0.00 & 0.15 & -0.01 & -0.13 & -0.01 \\
\hline Medial parietal & -0.17 & 0.04 & 0.17 & 0.29 & -0.09 & 0.04 \\
\hline Lateral parietal & $-0.20^{\mathrm{a}}$ & 0.02 & 0.25 & 0.33 & -0.13 & -0.00 \\
\hline Frontal & -0.10 & 0.09 & 0.21 & 0.33 & -0.07 & 0.04 \\
\hline Occipital & $-0.22^{a}$ & -0.15 & 0.15 & 0.30 & -0.18 & -0.07 \\
\hline \multicolumn{7}{|c|}{$\left[{ }^{18} \mathrm{~F}\right]$ flortaucipir $\mathrm{BP}_{\mathrm{ND}}$} \\
\hline \multicolumn{7}{|l|}{ Entorhinal region } \\
\hline Medial temporal & $-0.42^{b}$ & $-0.45^{b}$ & -0.14 & -0.22 & $-0.26^{\mathrm{a}}$ & $-0.27^{\mathrm{a}}$ \\
\hline Lateral temporal & $-0.33^{b}$ & $-0.31^{b}$ & -0.09 & -0.16 & -0.23 & -0.20 \\
\hline Medial parietal & $-0.27^{b}$ & $-0.27^{b}$ & -0.08 & -0.16 & 0.18 & -0.15 \\
\hline Lateral parietal & $-0.31^{b}$ & $-0.29^{b}$ & -0.10 & -0.21 & -0.16 & -0.12 \\
\hline Frontal & $-0.23^{\mathrm{a}}$ & $-0.25^{\mathrm{a}}$ & -0.19 & -0.32 & -0.11 & -0.09 \\
\hline Occipital & $-0.27^{b}$ & $-0.20^{\mathrm{a}}$ & -0.21 & -0.32 & -0.14 & -0.09 \\
\hline \multicolumn{7}{|l|}{ Limbic region } \\
\hline Medial temporal & $-0.38^{b}$ & $-0.40^{\mathrm{b}}$ & -0.14 & -0.20 & $-0.26^{a}$ & -0.23 \\
\hline Lateral temporal & $-0.48^{b}$ & $-0.46^{\mathrm{b}}$ & -0.07 & -0.18 & $-0.50^{b}$ & $-0.49^{\mathrm{b}}$ \\
\hline Medial parietal & $-0.41^{b}$ & $-0.43^{b}$ & -0.11 & -0.26 & $-0.41^{b}$ & $-0.40^{b}$ \\
\hline Lateral parietal & $-0.40^{\mathrm{b}}$ & $-0.41^{\mathrm{b}}$ & -0.01 & -0.26 & $-0.37^{\mathbf{b}}$ & $-0.35^{b}$ \\
\hline Frontal & $-0.31^{b}$ & $-0.34^{b}$ & -0.08 & -0.26 & $-0.29^{a}$ & $-0.28^{\mathrm{a}}$ \\
\hline Occipital & $-0.38^{b}$ & $-0.37^{\mathbf{b}}$ & -0.16 & -0.32 & $-0.37^{\mathbf{b}}$ & $-0.34^{b}$ \\
\hline \multicolumn{7}{|l|}{ Neocortical region } \\
\hline Medial temporal & $-0.32^{b}$ & $-0.33^{b}$ & -0.01 & -0.08 & -0.18 & -0.20 \\
\hline Lateral temporal & $-0.47^{b}$ & $-0.48^{b}$ & -0.06 & -0.13 & $-0.48^{b}$ & $-0.47^{\mathrm{b}}$ \\
\hline Medial parietal & $-0.45^{b}$ & $-0.48^{b}$ & -0.09 & -0.18 & $-0.49^{\mathrm{b}}$ & $-0.49^{b}$ \\
\hline Lateral parietal & $-0.49^{b}$ & $-0.51^{b}$ & -0.00 & -0.12 & $-0.50^{b}$ & $-0.49^{b}$ \\
\hline Frontal & $-0.39^{b}$ & $-0.44^{\mathrm{b}}$ & -0.11 & -0.24 & $-0.41^{\mathrm{b}}$ & $-0.40^{\mathrm{b}}$ \\
\hline Occipital & $-0.47^{\mathrm{b}}$ & $-0.47^{\mathrm{b}}$ & -0.18 & -0.28 & $-0.50^{b}$ & $-0.42^{b}$ \\
\hline
\end{tabular}

Standardized $\beta$ coefficients (significant in bold) from multiple regression analysis with gray matter density as the dependent variable and either CSF p-tau and/or $\left[{ }^{18} \mathrm{~F}\right]$ flortaucipir $\mathrm{BP}_{\mathrm{ND}}$ as predictors using separate analyses

Model $1=$ Either CSF p-tau or entorhinal/limbic/neocortical $\left[{ }^{18} \mathrm{~F}\right]$ flortaucipir $\mathrm{BP}_{\mathrm{ND}}$ was used as a predictor. Effects adjusted for age, sex, intracranial volume, and time lag between MRI and LP or $\left[{ }^{18} \mathrm{~F}\right]$ flortaucipir PET

Model 2 = CSF p-tau + neocortical $\left[{ }^{18} \mathrm{~F}\right]$ flortaucipir $\mathrm{BP}_{\mathrm{ND}}$ or entorhinal/limbic/neocortical $\left[{ }^{18} \mathrm{~F}\right]$ flortaucipir $\mathrm{BP}_{\mathrm{ND}}+\mathrm{CSF}$ p-tau were used as predictors. Effects adjusted as model 1

${ }^{\text {a }}$ Significant standardized $\beta$ coefficient at $p<0.05$

${ }^{\mathrm{b}}$ Significant standardized $\beta$ coefficient at $p<0.01$
PET with later markers of disease severity, such as atrophy and cognition [52, 53].

After the initial early rise of CSF p-tau, it may have limited longitudinal changes in prodromal / AD dementia stages [54-56]. However, $\left[{ }^{18} \mathrm{~F}\right]$ flortaucipir binding continues to increase over time $[57,58]$ suggesting a better ability for $\left[{ }^{18} \mathrm{~F}\right]$ flortaucipir PET to dynamically track neurodegeneration and/or (changes in) cognition $[59,60]$ on the clinical stage of the disease. This is in line with our study, in which we observed that regional $\left[{ }^{18} \mathrm{~F}\right]$ flortaucipir PET values were higher for $\mathrm{MCI} / \mathrm{AD}$ patients than for SCD subject with similar p-tau values (Fig. 1). These findings underscore that tau PET may be a more robust marker for disease severity in clinical AD than CSF p-tau, and that tau PET may serve as an important outcome variable for tracking disease severity, for instance, during treatment with disease-modifying or symptomatic drugs. The early plateauing of CSF p-tau 
in the prodromal phase of $\mathrm{AD}$ may also explain the lack of correlation of p-tau and tau PET in MCI/AD patients. Indeed CSF $p$-tau tends to solely increase in $A \beta+\operatorname{cog}$ nitively normal individuals and patients with $\mathrm{MCI}$ and stabilize or even decrease in AD dementia [54]. Alternatively, results may be partly be explained by differences in age (65 years (present study) vs. 7477 years) $[10,11]$. Early onset $\mathrm{AD}$ harbors a greater tau pathology burden and faster progression than late onset $\mathrm{AD}[61,62]$, and studies have shown that age could affect the levels of p-tau [63] and the amount of $\left[{ }^{18} \mathrm{~F}\right]$ flortaucipir uptake $[18,64]$.

In line with earlier studies [8], we observed a tight link between CSF p-tau and $\left[{ }^{18} \mathrm{~F}\right]$ flortaucipir $\mathrm{BP}_{\mathrm{ND}}$ in SCD. However, other studies did not find a relationship between CSF p-tau and $\left[{ }^{18} \mathrm{~F}\right]$ flortaucipir within cognitively unimpaired controls [9-11], which could be related to the notion that individuals with SCD are at increased risk for $\mathrm{AD}[65,66,67]$. However, p-tau may be more sensitive in early stages than $\left[{ }^{18} \mathrm{~F}\right]$ flortaucipir $[11,26,52]$, as subtle increases in $\left[{ }^{18} \mathrm{~F}\right]$ flortaucipir binding has been shown in the preclinical stages of $\mathrm{AD}[15,19,60,68]$.

Additionally, by using quantitative $\left[{ }^{18} \mathrm{~F}\right]$ flortaucipir $\mathrm{BP}_{\mathrm{ND}}$, we may have been able to capture modest increases in $\left[{ }^{18} \mathrm{~F}\right]$ flortaucipir uptake in $\mathrm{SCD}$ subjects, since we are able to measure small effects with $\mathrm{BP}_{\mathrm{ND}}$ with higher test-rest accuracy than SUVr [69]. Although in this study, we observed comparable results if we replace $\mathrm{BP}_{\mathrm{ND}}$ with $\mathrm{SUVr}$. In line with the previous studies, we found that $\mathrm{SUVr}$ overestimated $\mathrm{BP}_{\mathrm{ND}}$ [70]; however, this appeared to only marginally affect the associations of $\mathrm{p}$-tau and tau PET.

\section{Strengths and limitations}

The strength of this study is that we used the dynamic tau PET scans resulting in specific tracer to tau binding rather than a semi-quantitative approach (i.e., SUVr) which overestimates true tracer binding as shown in this study.

In addition, we examined these associations between the different tau biomarkers in SCD subjects instead of cognitively unimpaired individuals without cognitive complaints. By not using controls from a populations study, these results may be more generalizable to a memory clinic cohort.

We acknowledge that there was a time lag in our study between CSF tau sampling and performing of the tau PET scan. Ideally, CSF would be collected on the day of the PET scan, and although our results were comparable if we adjusted the time lag between CSF p-tau and tau PET to a maximum of 1 year and we entered the time lag as a covariate in our main analysis, this time lag may have affected our results. Since p- tau levels may rise before tau PET [11, 26, 52], associations may have been stronger when there was a greater time lag.

\section{Conclusion}

Regional $\left[{ }^{18} \mathrm{~F}\right]$ flortaucipir PET, more than CSF p-tau, relates to important clinical parameters of disease severity of $\mathrm{AD}$, i.e., cognition and neurodegeneration. As such, tau PET may more accurately reflect disease severity in $\mathrm{AD}$ than $\mathrm{p}$-tau.

Acknowledgments We kindly thank all participants for their contribution. Research of Amsterdam Alzheimer Center is part of the Neurodegeneration program of Amsterdam Neuroscience. The Amsterdam Alzheimer Center is supported by Alzheimer Nederland and Stichting VUmc funds. $\left[{ }^{18} \mathrm{~F}\right]$ Flortaucipir PET scans were made possible by Avid Radiopharmaceuticals Inc.

Funding information This study was funded by a ZonMW Memorabel grant.

\section{Compliance with ethical standards}

Conflict of interest Wolters, Ossenkoppele, Verfaillie, Coomans, Timmers, Visser, Tuncel, Boellaard, Windhorst, and Teunissen declare that they have no conflict of interest. Van der Flier received grant support from ZonMW, NWO, EU-FP7, Alzheimer Nederland, CardioVascular Onderzoek Nederland, Stichting Dioraphte, Gieskes-Strijbis Fonds, Boehringer Ingelheim, Piramal Neuroimaging, Roche BV, Janssen Stellar, Combinostics. All funding is paid to the institution. WvdF holds the Pasman chair. Van Berckel received research support from ZON-MW, AVID radiopharmaceuticals, CTMM and Janssen Pharmaceuticals. He is a trainer for Piramal and GE. He receives no personal honoraria. Scheltens received grant support (to the institution) from GE Healthcare, Danone Research, Piramal, and MERCK. In the past 2 years he has received consultancy/speaker fees from Lilly, GE Healthcare, Novartis, Forum, Sanofi, Nutricia, Probiodrug, and EIP Pharma. All funding is paid to the institution. No other potential conflicts of interest relevant to this article exist.

Ethical approval All procedures performed in studies involving human participants were in accordance with the ethical standards of the institutional and/or national research committee and with the 1964 Helsinki declaration and its later amendments or comparable ethical standards.

Informed consent Informed consent was obtained from all individual participants included in the study.

Open Access This article is licensed under a Creative Commons Attribution 4.0 International License, which permits use, sharing, adaptation, distribution and reproduction in any medium or format, as long as you give appropriate credit to the original author(s) and the source, provide a link to the Creative Commons licence, and indicate if changes were made. The images or other third party material in this article are included in the article's Creative Commons licence, unless indicated otherwise in a credit line to the material. If material is not included in the article's Creative Commons licence and your intended use is not permitted by statutory regulation or exceeds the permitted use, you will need to obtain permission directly from the copyright holder. To view a copy of this licence, visit http://creativecommons.org/licenses/by/4.0/. 


\section{References}

1. Giannakopoulos P, Herrmann FR, Bussiere T, Bouras C, Kovari E, Perl DP, et al. Tangle and neuron numbers, but not amyloid load, predict cognitive status in Alzheimer's disease. Neurology. 2003;60:1495-500. https://doi.org/10.1212/01.wnl.0000063311.58879.01.

2. Nelson PT, Alafuzoff I, Bigio EH, Bouras C, Braak H, Cairns NJ, et al. Correlation of Alzheimer disease neuropathologic changes with cognitive status: a review of the literature. J Neuropathol Exp Neurol. 2012;71:362-81. https://doi.org/10.1097/NEN.0b013e31825018f7.

3. Arriagada PV, Growdon JH, Hedley-Whyte ET, Hyman BT. Neurofibrillary tangles but not senile plaques parallel duration and severity of Alzheimer's disease. Neurology. 1992;42:631. https://doi.org/10.1212/WNL.42.3.631.

4. Blennow K, Hampel H, Weiner M, Zetterberg H. Cerebrospinal fluid and plasma biomarkers in Alzheimer disease. Nat Rev Neurol. 2010;6:131-44. https://doi.org/10.1038/nrneurol.2010.4.

5. Chien DT, Bahri S, Szardenings AK, Walsh JC, Mu F, Su MY, et al. Early clinical PET imaging results with the novel PHF-tau radioligand [F-18]-T807. J Alzheimers Dis. 2013;34:457-68. https://doi.org/10.3233/JAD-122059.

6. Xia CF, Arteaga J, Chen G, Gangadharmath U, Gomez LF, Kasi D, et al. [(18)F]T807, a novel tau positron emission tomography imaging agent for Alzheimer's disease. Alzheimers Dement. 2013;9: 666-76. https://doi.org/10.1016/j.jalz.2012.11.008.

7. Marquie M, Normandin MD, Vanderburg CR, Costantino I, Bien EA, Rycyna LG, et al. Validating novel tau PET tracer [F-18]-AV1451 (T807) on postmortem brain tissue. Ann Neurol. 2015. https:// doi.org/10.1002/ana.24517.

8. Chhatwal JP, Schultz AP, Marshall GA, Boot B, Gomez-Isla T, Dumurgier J, et al. Temporal T807 binding correlates with CSF tau and phospho-tau in normal elderly. Neurology. 2016;87:9206. https://doi.org/10.1212/Wnl.0000000000003050.

9. Gordon BA, Friedrichsen K, Brier M, Blazey T, Su Y, Christensen J, et al. The relationship between cerebrospinal fluid markers of Alzheimer pathology and positron emission tomography tau imaging. Brain. 2016;139:2249-60. https://doi.org/10.1093/brain/aww139.

10. Brier MR, Gordon B, Friedrichsen K, McCarthy J, Stern A, Christensen J, et al. Tau and Abeta imaging, CSF measures, and cognition in Alzheimer's disease. Sci Transl Med. 2016;8:338ra66. https://doi.org/10.1126/scitranslmed.aaf2362.

11. Mattsson N, Scholl M, Strandberg O, Smith R, Palmqvist S, Insel PS, et al. (18)F-AV-1451 and CSF T-tau and P-tau as biomarkers in Alzheimer's disease. EMBO Mol Med. 2017;9:1212-23. https:// doi.org/10.15252/emmm.201707809.

12. Mattsson N, Smith R, Strandberg O, Palmqvist S, Scholl M, Insel PS, et al. Comparing (18)F-AV-1451 with CSF t-tau and p-tau for diagnosis of Alzheimer disease. Neurology. 2018;90:e388-e95. https://doi.org/10.1212/WNL.0000000000004887.

13. Wallin AK, Blennow K, Zetterberg H, Londos E, Minthon L, Hansson O. CSF biomarkers predict a more malignant outcome in Alzheimer disease. Neurology. 2010;74:1531-7. https://doi.org/10. 1212/WNL.0b013e3181dd4dd8.

14. Herukka SK, Pennanen C, Soininen H, Pirttila T. CSF A beta 42, tau and phosphorylated tau correlate with medial temporal lobe atrophy (vol 14, pg 51, 2008). J Alzheimers Dis. 2008;15:347.

15. Scholl M, Lockhart SN, Schonhaut DR, O'Neil JP, Janabi M, Ossenkoppele R, et al. PET imaging of tau deposition in the aging human brain. Neuron. 2016;89:971-82. https://doi.org/10.1016/j. neuron.2016.01.028.

16. Aschenbrenner AJ, Gordon BA, Benzinger TLS, Morris JC, Hassenstab JJ. Influence of tau PET, amyloid PET, and hippocampal volume on cognition in Alzheimer disease. Neurology. 2018;91:e859 e66. https://doi.org/10.1212/WNL.0000000000006075.
17. Johnson KA, Schultz A, Betensky RA, Becker JA, Sepulcre J, Rentz D, et al. Tau positron emission tomographic imaging in aging and early Alzheimer disease. Ann Neurol. 2016;79:110-9. https:// doi.org/10.1002/ana.24546.

18. Ossenkoppele R, Schonhaut DR, Scholl M, Lockhart SN, Ayakta N, Baker SL, et al. Tau PET patterns mirror clinical and neuroanatomical variability in Alzheimer's disease. Brain. 2016;139:155167. https://doi.org/10.1093/brain/aww027.

19. Ossenkoppele R, Smith R, Ohlsson T, Strandberg O, Mattsson N, Insel PS, et al. Associations between tau, Abeta, and cortical thickness with cognition in Alzheimer disease. Neurology. 2019;92: e601-e12. https://doi.org/10.1212/WNL.0000000000006875.

20. Wang L, Benzinger TL, Su Y, Christensen J, Friedrichsen K, Aldea P, et al. Evaluation of tau imaging in staging Alzheimer disease and revealing interactions between beta-amyloid and tauopathy. Jama Neurol. 2016;73:1070-7. https://doi.org/10.1001/jamaneurol.2016.2078.

21. Iaccarino L, Tammewar G, Ayakta N, Baker SL, Bejanin A, Boxer $\mathrm{AL}$, et al. Local and distant relationships between amyloid, tau and neurodegeneration in Alzheimer's disease. Neuroimage Clin. 2018;17:452-64. https://doi.org/10.1016/j.nicl.2017.09.016.

22. Maass A, Landau S, Baker SL, Horng A, Lockhart SN, La Joie R, et al. Comparison of multiple tau-PET measures as biomarkers in aging and Alzheimer's disease. Neuroimage. 2017;157:448-63. https://doi.org/10.1016/j.neuroimage.2017.05.058.

23. Buerger K, Alafuzoff I, Ewers M, Pirttila T, Zinkowski R, Hampel H. No correlation between CSF tau protein phosphorylated at threonine 181 with neocortical neurofibrillary pathology in Alzheimer's disease. Brain. 2007;130:e82. https://doi.org/10.1093/brain/awm140.

24. Engelborghs S, Sleegers K, Cras P, Brouwers N, Serneels S, De Leenheir E, et al. No association of CSF biomarkers with APOEepsilon4, plaque and tangle burden in definite Alzheimer's disease. Brain. 2007;130:2320-6. https://doi.org/10.1093/brain/awm136.

25. Sato C, Barthelemy NR, Mawuenyega KG, Patterson BW, Gordon BA, Jockel-Balsarotti J, et al. Tau kinetics in neurons and the human central nervous system. Neuron. 2018;97:1284-98 e7. https://doi. org/10.1016/j.neuron.2018.02.015.

26. Meyer PF, Binette AP, Gonneaud J, Breitner JCS, Villeneuve S. Characterization of Alzheimer disease biomarker discrepancies using cerebrospinal fluid phosphorylated tau and AV1451 positron emission tomography. JAMA Neurol. 2020. https://doi.org/10. 1001/jamaneurol.2019.4749.

27. Golla SSV, Timmers T, Ossenkoppele R, Groot C, Verfaillie S, Scheltens P, et al. Quantification of tau load using [(18)F]AV1451 PET. Mol Imaging Biol. 2017;19:963-71. https://doi.org/10.1007/ s11307-017-1080-z.

28. Lammertsma AA. Forward to the past: the case for quantitative PET imaging. J Nucl Med. 2017;58:1019-24. https://doi.org/10.2967/ jnumed.116.188029.

29. van der Flier WM, Pijnenburg YA, Prins N, Lemstra AW, Bouwman FH, Teunissen CE, et al. Optimizing patient care and research: the Amsterdam dementia cohort. J Alzheimers Dis. 2014;41:313-27. https://doi.org/10.3233/JAD-132306.

30. van der Flier WM, Scheltens P. Amsterdam dementia cohort: performing research to optimize care. J Alzheimers Dis. 2018;62: 1091-111. https://doi.org/10.3233/JAD-170850.

31. Albert MS, DeKosky ST, Dickson D, Dubois B, Feldman HH, Fox $\mathrm{NC}$, et al. The diagnosis of mild cognitive impairment due to Alzheimer's disease: recommendations from the National Institute on Aging-Alzheimer's Association workgroups on diagnostic guidelines for Alzheimer's disease. Alzheimers Dement. 2011;7: 270-9. https://doi.org/10.1016/j.jalz.2011.03.008.

32. McKhann GM, Knopman DS, Chertkow H, Hyman BT, Jack CR $\mathrm{Jr}$, Kawas CH, et al. The diagnosis of dementia due to Alzheimer's disease: recommendations from the National Institute on AgingAlzheimer's Association workgroups on diagnostic guidelines for 
Alzheimer's disease. Alzheimers Dement. 2011;7:263-9. https:// doi.org/10.1016/j.jalz.2011.03.005.

33. Jessen F, Amariglio RE, van Boxtel M, Breteler M, Ceccaldi M, Chetelat G, et al. A conceptual framework for research on subjective cognitive decline in preclinical Alzheimer's disease. Alzheimers Dement. 2014;10:844-52. https://doi.org/10.1016/j.jalz.2014.01.001.

34. Golla SS, Verfaillie SC, Boellaard R, Adriaanse SM, Zwan MD, Schuit RC, et al. Quantification of [(18)F]florbetapir: a test-retest tracer kinetic modelling study. J Cereb Blood Flow Metab. 2018: 271678X18783628. https://doi.org/10.1177/0271678X18783628.

35. Duits FH, Teunissen CE, Bouwman FH, Visser PJ, Mattsson N, Zetterberg H, et al. The cerebrospinal fluid "Alzheimer profile": easily said, but what does it mean? Alzheimers Dement. 2014;10: 713-23 e2. https://doi.org/10.1016/j.jalz.2013.12.023.

36. Seibyl J, Catafau AM, Barthel H, Ishii K, Rowe CC, Leverenz JB, et al. Impact of training method on the robustness of the visual assessment of 18F-Florbetaben PET scans: results from a Phase-3 study. J Nucl Med. 2016;57:900-6. https://doi.org/10.2967/jnumed.115.161927.

37. Zwan M, van Harten A, Ossenkoppele R, Bouwman F, Teunissen $\mathrm{C}$, Adriaanse S, et al. Concordance between cerebrospinal fluid biomarkers and [11C]PIB PET in a memory clinic cohort. Journal of Alzheimer's disease : JAD. 2014;41:801-7. https://doi.org/10. 3233/JAD-132561.

38. Teunissen CE, Petzold A, Bennett JL, Berven FS, Brundin L, Comabella M, et al. A consensus protocol for the standardization of cerebrospinal fluid collection and biobanking. Neurology. 2009;73: 1914-22. https://doi.org/10.1212/WNL.0b013e3181c47cc2.

39. Tijms BM, Willemse EAJ, Zwan MD, Mulder SD, Visser PJ, van Berckel BNM, et al. Unbiased approach to counteract upward drift in cerebrospinal fluid Amyloid-beta 1-42 analysis results. Clin Chem. 2018;64:576-85. https://doi.org/10.1373/clinchem.2017.281055.

40. Mulder C, Verwey NA, van der Flier WM, Bouwman FH, Kok A, van Elk EJ, et al. Amyloid-beta(1-42), total tau, and phosphorylated tau as cerebrospinal fluid biomarkers for the diagnosis of Alzheimer disease. Clin Chem. 2010;56:248-53. https://doi.org/10.1373/ clinchem.2009.130518.

41. Folstein MF, Folstein SE, McHugh PR. "Mini-mental state". A practical method for grading the cognitive state of patients for the clinician. J Psychiatr Res. 1975;12:189-98.

42. Groot C, van Loenhoud AC, Barkhof F, van Berckel BN, Koene T, Teunissen CC, et al. Differential effects of cognitive reserve and brain reserve on cognition in Alzheimer disease. Neurology. 2018;90:e149-e56.

43. Timmers T, Ossenkoppele R, Wolters EE, Verfaillie SCJ, Visser D, Golla SSV, et al. Associations between quantitative [(18)F]flortaucipir tau PET and atrophy across the Alzheimer's disease spectrum. Alzheimers Res Ther. 2019;11:60. https://doi.org/ 10.1186/s13195-019-0510-3.

44. Golla SSV, Timmers T, Ossenkoppele R, Groot C, Verfaillie S, Scheltens P, et al. Quantification of tau load using [18F]AV1451 PET. Mol Imaging Biol. 2017;19:963-71. https://doi.org/10.1007/ s11307-017-1080-z.

45. Wolters EE, Golla SSV, Timmers T, Ossenkoppele R, van der Weijden CWJ, Scheltens P, et al. A novel partial volume correction method for accurate quantification of [(18)F] flortaucipir in the hippocampus. EJNMMI Res. 2018;8:79. https://doi.org/10.1186/ s13550-018-0432-2.

46. Vollmar S, Michel C, Treffert JT, Newport DF, Casey M, Knoss C, et al. HeinzelCluster: accelerated reconstruction for FORE and OSEM3D. Phys Med Biol. 2002;47:2651-8.

47. Hammers A, Allom R, Koepp MJ, Free SL, Myers R, Lemieux L, et al. Three-dimensional maximum probability atlas of the human brain, with particular reference to the temporal lobe. Hum Brain Mapp. 2003;19:224-47. https://doi.org/10.1002/hbm.10123.

48. Svarer C, Madsen K, Hasselbalch SG, Pinborg LH, Haugbol S, Frokjaer $\mathrm{VG}$, et al. MR-based automatic delineation of volumes of interest in human brain PET images using probability maps. Neuroimage. 2005;24:969-79. https://doi.org/10.1016/j.neuroimage.2004.10.017.

49. Landis R. Standardized Regression Coefficients. Encyclopedia of statistics in behavioral Science 2005.

50. La Joie R, Bejanin A, Fagan AM, Ayakta N, Baker SL, Bourakova $\mathrm{V}$, et al. Associations between [(18)F]AV1451 tau PET and CSF measures of tau pathology in a clinical sample. Neurology. 2018;90: e282-e90. https://doi.org/10.1212/WNL.0000000000004860.

51. Palmqvist S, Insel PS, Stomrud E, Janelidze S, Zetterberg H, Brix $\mathrm{B}$, et al. Cerebrospinal fluid and plasma biomarker trajectories with increasing amyloid deposition in Alzheimer's disease. EMBO Mol Med. 2019:e11170. https://doi.org/10.15252/emmm.201911170.

52. Sato C, Barthelemy NR, Mawuenyega KG, Patterson BW, Gordon BA, Jockel-Balsarotti J, et al. Tau kinetics in neurons and the human central nervous system. Neuron. 2018;98:861-4. https://doi.org/10. 1016/j.neuron.2018.04.035.

53. Jack CR, Holtzman DM. Biomarker modeling of Alzheimer's disease. Neuron. 2013;80:1347-58. https://doi.org/10.1016/j.neuron. 2013.12.003.

54. Sutphen CL, McCue L, Herries EM, Xiong C, Ladenson JH, Holtzman DM, et al. Longitudinal decreases in multiple cerebrospinal fluid biomarkers of neuronal injury in symptomatic late onset Alzheimer's disease. Alzheimers Dement. 2018;14:869-79. https:// doi.org/10.1016/j.jalz.2018.01.012.

55. Buchhave P, Minthon L, Zetterberg H, Wallin AK, Blennow K, Hansson O. Cerebrospinal fluid levels of $\beta$-amyloid 1-42, but not of tau, are fully changed already 5 to 10 years before the onset of Alzheimer dementia. Arch Gen Psychiatry. 2012;69:98-106. https://doi.org/10.1001/archgenpsychiatry.2011.155.

56. Blennow K, Zetterberg H, Minthon L, Lannfelt L, Strid S, Annas P, et al. Longitudinal stability of CSF biomarkers in Alzheimer's disease. Neurosci Lett. 2007;419:18-22. https://doi.org/10.1016/j. neulet.2007.03.064.

57. Jack CR Jr, Wiste HJ, Schwarz CG, Lowe VJ, Senjem ML, Vemuri $\mathrm{P}$, et al. Longitudinal tau PET in ageing and Alzheimer's disease. Brain. 2018;141:1517-28. https://doi.org/10.1093/brain/awy059.

58. Pontecorvo MJ, Devous MD, Kennedy I, Navitsky M, Lu M, Galante N, et al. A multicentre longitudinal study of flortaucipir $(18 \mathrm{~F})$ in normal ageing, mild cognitive impairment and Alzheimer's disease dementia. Brain. 2019;142:1723-35. https:// doi.org/10.1093/brain/awz090.

59. Harrison TM, La Joie R, Maass A, Baker SL, Swinnerton K, Fenton L, et al. Longitudinal tau accumulation and atrophy in aging and alzheimer disease. Ann Neurol. 2019;85:229-40. https://doi.org/10.1002/ana. 25406.

60. Hanseeuw BJ, Betensky RA, Jacobs HIL, Schultz AP, Sepulcre J, Becker JA, et al. Association of amyloid and tau with cognition in preclinical Alzheimer disease: a longitudinal study. JAMA Neurol. 2019. https://doi.org/10.1001/jamaneurol.2019.1424.

61. Berg L, McKeel DW Jr, Miller JP, Storandt M, Rubin EH, Morris JC, et al. Clinicopathologic studies in cognitively healthy aging and Alzheimer's disease: relation of histologic markers to dementia severity, age, sex, and apolipoprotein E genotype. Arch Neurol. 1998;55:326-35. https://doi.org/10.1001/archneur.55.3.326.

62. Ho GJ, Hansen LA, Alford MF, Foster K, Salmon DP, Galasko D, et al. Age at onset is associated with disease severity in Lewy body variant and Alzheimer's disease. Neuroreport. 2002;13:1825-8. https://doi.org/10.1097/00001756-200210070-00028.

63. Mattsson N, Rosen E, Hansson O, Andreasen N, Parnetti L, Jonsson $\mathrm{M}$, et al. Age and diagnostic performance of Alzheimer disease CSF biomarkers. Neurology. 2012;78:468-76. https://doi. org/10.1212/WNL.0b013e3182477eed.

64. Scholl M, Ossenkoppele R, Strandberg O, Palmqvist S. Swedish bio Fs, Jogi J, et al. distinct 18F-AV-1451 tau PET retention patterns in early- and late-onset Alzheimer's disease. Brain. 2017;140:228694. https://doi.org/10.1093/brain/awx171. 
65. Slot RER, Verfaillie SCJ, Overbeek JM, Timmers T, Wesselman LMP, Teunissen CE, et al. Subjective cognitive impairment cohort (SCIENCe): study design and first results. Alzheimers Res Ther. 2018;10:76. https://doi.org/10.1186/s13195-018-0390-y.

66. Slot RER, Sikkes SAM, Berkhof J, Brodaty H, Buckley R, Cavedo E, et al. Subjective cognitive decline and rates of incident Alzheimer's disease and non-Alzheimer's disease dementia. Alzheimers Dement. 2019;15:465-76. https://doi.org/10.1016/j. jalz.2018.10.003.

67. Timmers T, Ossenkoppele R, Verfaillie SCJ, van der Weijden CWJ, Slot RER, Wesselman LMP, et al. Amyloid PET and cognitive decline in cognitively normal individuals: the SCIENCe project. Neurobiol Aging. 2019;79:50-8. https://doi.org/10.1016/j. neurobiolaging.2019.02.020.

68. Sperling RA, Mormino EC, Schultz AP, Betensky RA, Papp KV, Amariglio RE, et al. The impact of amyloid-beta and tau on prospective cognitive decline in older individuals. Ann Neurol. 2019;85:181-93. https://doi.org/10.1002/ana.25395.

69. Timmers T, Ossenkoppele R, Visser D, Tuncel H, Wolters E, Verfaillie SCJ, et al. Test-retest repeatability of [18F]flortaucipir PET in Alzheimer's disease and cognitively normal individuals. $\mathrm{J}$ Cereb Blood Flow Metab. 2019; in press.

70. van Berckel BN, Ossenkoppele R, Tolboom N, Yaqub M, FosterDingley JC, Windhorst AD, et al. Longitudinal amyloid imaging using 11C-PiB: methodologic considerations. J Nucl Med. 2013;54:1570-6. https://doi.org/10.2967/jnumed.112.113654.

Publisher's note Springer Nature remains neutral with regard to jurisdictional claims in published maps and institutional affiliations. 